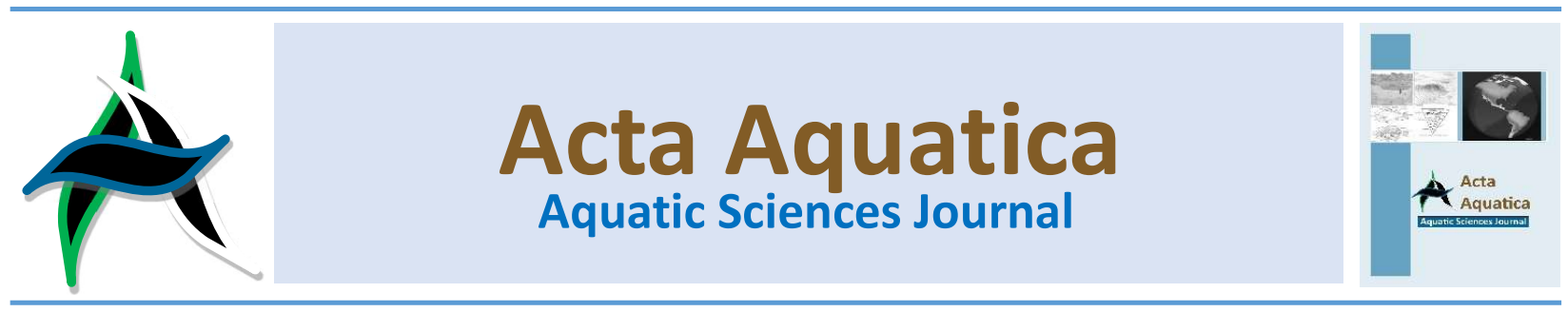

\title{
Penetasan telur penyu sisik (Eretmochelys imbricata) dengan kedalaman yang berbeda
}

\section{Hatchling hawksbill sea turtle eggs (Eretmochelys imbricata) with different nest depth}

\author{
Erlangga $^{a *}$, Ayu Lestari $^{b}$, Zulfikar $^{a}$, Munawar Khalila ${ }^{a}$, dan Riri Ezraneti ${ }^{a}$ \\ a Program Studi Ilmu Kelautan, Fakultas Pertanian, Universitas Malikussaleh \\ ${ }^{b}$ Program Studi Budidaya Perairan, Fakultas Pertanian, Universitas Malikussaleh
}

\begin{abstract}
Abstrak
Penelitian ini dilaksanakan dibulan November 2018 sampai dengan Januari 2019 yang bertempat di UPTD Konservasi dan Pengawasan Sumberdaya Kelautan dan Perikanan Sumatera Barat Kota Pariaman, Penelitian ini bertujuan untuk mengetahui tingkat persentase daya tetas telur penyu sisik (Eretmochelys imbricata) berdasarkan perbedaan kedalaman sarang. Metode yang digunakan pada penelitian ini adalah metode Rancangan acak Kelompok (RAK) Non factorial yang terdiri dari 3 perlakuan dan 3 ulangan. Adapun perlakuan yang digunakan adalah Perlakuan A (dengan kedalaman sarang inkubasi $30 \mathrm{~cm}$ ), Perlakuan B (dengan kedalaman sarang inkubasi $40 \mathrm{~cm}$ ), dan Perlakuan C (dengan kedalaman sarang inkubasi $50 \mathrm{~cm}$ ). Hasil penelitian persentase penetasan telur penyu sisik ini berpengaruh sangat nyata, persentase penetasan terbaik terdapat pada perlakuan $\mathrm{A}(30 \mathrm{~cm})$ dengan persentase penetasan $78 \%$ menetas di pukul 06:00 wib dengan kisaran suhu penetasan $24-28^{\circ} \mathrm{C}, \mathrm{pH}$ penetasan $6,6-6,8$, dan pasir inkubasi berukuran sedang dengan ukuran $0,150 \mathrm{~mm}$ dengan berat mencapai 461 gram.
\end{abstract}

Kata kunci: Penyu sisik, Persentase penetasan, $p H$, Suhu

\section{Abstract}

This research was conducted from November 2018 until January 2019 which was held at the UPTD Conservation and Supervision of Marine Resources and Fisheries in West Sumatera, Pariaman City. The aim of the research is to know hatchling hawksbill sea turtle eggs based on nest depth. The method used in this study is a nonfactorial randomized block design ( $\mathrm{RBD}$ ) consisting of 3 treatments and 3 replications. The treatments used were treatment $A$ (with a depth of $30 \mathrm{~cm}$ incubation nest), treatment $B$ (with a depth of incubation nest $40 \mathrm{~cm}$ ), and Treatment $C$ (with a depth of incubation nest 50 $\mathrm{cm}$ ). The results of this study showed that hatching hawksbill eggs hatched very significantly, the best hatching percentage was in treatment $A(30 \mathrm{~cm})$ with $78 \%$ hatching at $6: 00$ a.m. with hatching temperature range of $24-28^{\circ} \mathrm{C}$, hatching $\mathrm{pH}$ of $6,6-6,8$ and medium sized incubation sand with a size of $0.150 \mathrm{~mm}$ with a weight reaching 461 grams.

Keywords: Hatching percentage, Hawksbill turtle, $\mathrm{pH}$, Temperature

\footnotetext{
* Korespondensi: Prodi Ilmu Kelautan, Fakultas Pertanian, Universitas Malikussaleh. Kampus utama Reuleut, Kabupaten Aceh Utara, Aceh, Indonesia. Tel: +62-645-57320 Fax: +62-645-44450. e-mail: erlangga@unimal.ac.id
} 


\section{Pendahuluan}

\subsection{Latar belakang}

Penyu laut dijumpai di semua laut tropis dan daerah sub tropis. Mayoritas penyu laut bertempat tinggal diperairan yang dangkal sepanjang pantai dan sekitar pulau, tetapi beberapa diantaranya melakukan migrasi ke tempat yang jauh dan sering dijumpai di laut terbuka. Setelah musim bertelur, beberapa spesies membenamkan dirinya dalam dasar perairan berlumpur di perairan pantai yang dangkal atau melakukan migrasi ke wilayah yang lebih hangat untuk menghindari musim dingin.

Perairan laut Indonesia menjadi habitat 6 jenis penyu dari 7 jenis penyu yang ada di dunia. Enam jenis penyu yang ada di Indonesia adalah penyu hijau (Chelonia mydas), penyu lengkang (Lepidochelys olivacea), penyu tempayan (Caretta caretta), penyu sisik (Eretmochelys imbricata), penyu belimbing (Dermochelyscoriacea) dan penyu pipih (Natator depressus). Penyu sisik umumnya dapat dikatakan penyu dewasa pada umur 20-25 tahun. Penyu sisik dapat beruaya dari habitat pakan ke ruaya reproduksi, untuk melakukan reproduksi. Pada siklus reproduksi penyu jantan dan penyu betina akan berdua-duaan dan penyu jantan akan bertengker di atas penyu betina, proses ini akan berlangsung kurang lebih selama 6 jam. Seminggu setelah proses reproduksi berlangsung penyu betina menyimpan sperma jantan didalam tubuhnya dan proses pembuahan terjadi didalam tubuh penyu betina. Penyu betina akan kembali kedaratan atau pantai untuk bertelur, pantai yang akan dipilih oleh penyu betina ialah pantai dimana dia ditetaskan puluhan tahun yang lalu. Penyu betina akan menggali sendiri sarang untuk telurnya menggunakan flipper depan dan flipper belakang. Dalam sekali bertelur penyu betina dapat mengeluarkan telurnya 200 butir bahkan bisa lebih, penyu betina akan meninggalkan sarang telurnya setelah bertelur.

Semua jenis penyu yang ada di dunia saat ini berada dalam kondisi yang terancam oleh berbagai hal, terutama pengambilan telur oleh manusia, selain manusia kegagalan penetasan telur penyu juga dapat disebabkan oleh predator yang memangsa telur penyu sehingga gagal menetas. Telur penyu diketahui sangat rawan terhadap pemangsaan. Telur penyu umumnya dimakan oleh sebangsa musang, anjing, babi, monyet, kadal "varaqnid", kepiting hantu (ghost crabs), semut, dan juga serangan jamur dan bakteri. Ketika tukik sampai di air, pemangsaan umumya dilakukan oleh burung (dibagian permukaan) dan oleh ikan, seperti hiu dan ikan ikan predator lainnya.

Untuk menjaga telur penyu dari predator maka perlu dilakukan konservasi. Konservasi adalah upaya-upaya pelestarian lingkungan akan tetapi tetap memperhatikan manfaat yang bisa didapatkan pada saat itu dengan cara tetap mempertahankan keberadaan setiap komponen-komponen lingkungan untuk pemanfaatan di masa yang akan datang. Berbagai metode dilakukan untuk melakukan kegiatan konservasi penyu. Salah satunya dengan memperhatikan sarang inkubasi telur penyu. Kedalaman penyu dalam meletakkan telur dalam sarang akan mempengaruhi tingkat persentase penetasan telur penyu. oleh karena itu perlu penelitian untuk menentukan kedalaman yang optimal untuk dilakukan penanaman telur penyu sehingga mampu menghasilkan tingkat penetasan yang tinggi.

\subsection{Identifikasi Masalah}

Permasalahan dalam penetasan telur secara alami adalah banyaknya predator yang dapat merusak sarang penetasan sehingga gagal menetas. Secara alami penyu menanam telur nya untuk menghindari pemangsaan dari predator. Kedalaman sarang akan mempengaruhi persentase penetasan telur penyu dan juga akan mempengaruhi pergerakan tukik keluar dari sarang. Kedalaman sarang akan mempengaruhi faktor lingkungan lainnya dalam membantu percepatan penetasan telur penyu. Maka perlu dilakukan penelitian untuk menemukan kedalaman sarang yang mendukung dalam proses percepatan penetasan telur penyu dengan tingkat penetasan yang tinggi.

\subsection{Tujuan dan manfaat}

Tujuan penelitian ini adalah untuk mengetahui tingkat persentase daya tetas telur penyu sisik (Eretmochelys imbricata), berdasarkan perbedaan kedalaman sarang. Penelitian ini diharapkan sebagai acuan untuk kegiatan penetasan telur penyu dalam kegiatan konservasi/ pemeliharaan penyu.

\section{Metode Penelitian}

\subsection{Waktu dan tempat}

Penelitian ini dilaksanakan pada 26 November 2018 sampai 19 Januari 2019 dilaksanakan di UPTD Konservasi dan Pengawasan Sumberdaya Kelautan dan Perikanan Sumatera Barat. Jln. Syeh Abdul Arief Desa Apar Kecamatan Pariaman Utara Kota Pariaman Sumatera Barat.

\subsection{Bahan dan alat penelitian}

Adapun bahan penelitian yang digunakan dalam penelitian ini adalah telur penyu, pasir (media inkubasi) Sedangkan alat-alat yang digunakan dalam penelitian ini adalah $\mathrm{pH}$ tanah, thermometer, papan penanda, ember, meteran, saringan bertingkat, skop, kamera, buku tulis dan kebutuhan lainnya.

\subsection{Rancangan penelitian}

Penelitian ini menggunakan metode eksperimental, yang dilakukan untuk meneliti kedelaman sarang terhadap penetasan telur penyu. Rancangan penelitian yang digunakan adalah Rancangan Acak Lengkap (RAL), dengan tiga ulangan. Adapun perlakuan yang diberikan adalah:

Perlakuan A : Kedalaman sarang $30 \mathrm{~cm}$

Perlakuan B : Kedalaman sarang $40 \mathrm{~cm}$

Perlakuan C : Kedalaman sarang $50 \mathrm{~cm}$

\subsection{Prosedur penelitian}

\subsubsection{Persiapan sarang}

Penetasan telur penyu sisik dilakukan persiapan sarang penetasan telur, yakni dengan menggali sarang dengan kedalaman dan diameter yang berbeda sesuai dengan perlakuan dan ulangan. Penggalian dilakukan dengan menggunakan skop, mengukur kedalaman dan diameter sarang menggunakan penggaris atau meteran.

\subsubsection{Teknik Inkubasi Telur}

Telur-telur penyu akan diinkubasi didalam sarang yang telah digali sebelumnya, telur-telur penyu ini akan disusun rapi didalam sarang dan dilakukan dengan sangat hati-hati agar tidak merusak embrio telur. Area sarang akan diberi pengaman berupa jaring, agar sarang tetap terhindar dari serangan predator (biawak, anjing dII). Pada bagian atas akan ditutupi dengan kain hapa, hal ini dilakukan agar pantulan cahaya matahari tidak langsung terpancar ke pasir sarang. 


\subsection{Parameter uji}

\subsubsection{Jumlah telur menetas}

Persentase keberhasilan penetasan telur Penyu dihitung berdasarkan perbandingan antara jumlah telur yang menetas dengan jumlah seluruh telur yang diinkubasikan dalam sarang (Dermawan et al 2009)

$$
\text { HSs }=(\mathrm{Js} / \mathrm{Jts}) \times 100
$$

Keterangan:

HSs : Tingkat keberhasilan telur menetas (\%)

Js : Jumlah telur yang menetas (butir)

Jts : Jumlah telur dalam sarang (butir)

\subsubsection{Kecepatan penetasan}

Kecepatan penetasan telur penyu diukur dengan melihat waktu telur mulai di inkubasi sampai keseluruhan telur menetas

\subsubsection{Suhu penetasan}

Pengukuran suhu penetasan adalah dengan meletakkan thermometer didalam sarang inkubasi telur penyu pada semua perlakuan dan ulangan. proses pengukuran suhu dilakukan dari awal peletakan telur penyu sampai menetas.

\subsection{4. $\mathrm{pH}$ substrat peneluran}

Pengukuran $\mathrm{pH}$ pasir disini dilakukan setiap hari, pegukuran menggunakan alat $\mathrm{pH}$ tanah, pengukuran dilakukan setiap hari pagi, siang, dan sore pada masingmasing perlakuan dan ulangan.

\subsubsection{Ukuran partikel substrat peneluran}

Pengukuran partikel substrat dengan mengambil sample substrat pada setiap lapisan substrat didalam sarang pada semua perlakuan. Uji sample ini dilakukan di Laboratorium Tehnik Sipil Universitas Malikussaleh.

\subsection{Analisis data}

Penelitian ini menggunakan analisis varian Rancangan Acak Lengkap (RAL) dan Data yang diperoleh dari pengamatan akan disajikan dalam bentuk tabel dan grafik. Metode matematika untuk Rancangan Acak Lengkap (RAL) adalah sebagai berikut:

\section{Keterangan:}

$$
Y i j=\mu+\tau i+\varepsilon i j
$$

Yij : pengamatan perlakuan ke-i, Ulangan ke-j

$\mu \quad$ :Rataan Umum

זi : Pengaruh Perlakuan ke-i

cij : Pengaruh Galat ke-i dan Ulangan ke-j

Data hasil pengamatan dianalisis secara statistik dengan menggunakan analisis ragam (uji F) dan dilakukan uji lanjut.

\section{Hasil dan Pembahasan}

\subsection{Jumlah Telur Menetas}

Persentase penetasan telur penyu sisik (Eretmochelys imbricata) pada setiap kedalaman sarang yang berbeda dapat dilihat pada Gambar 1.

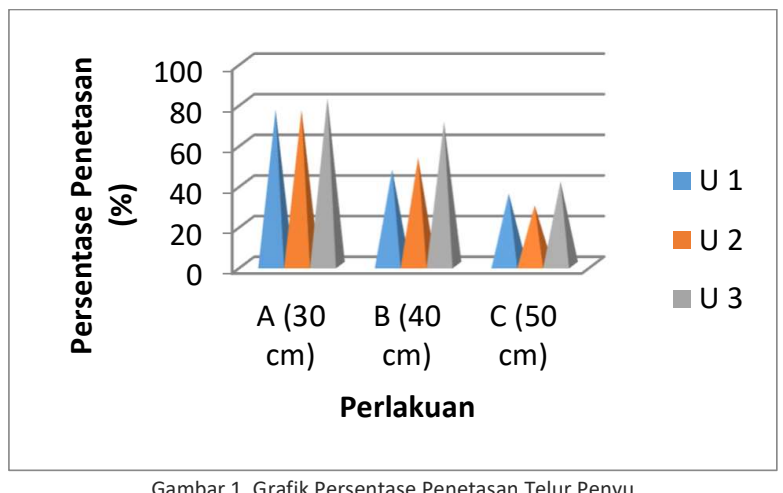

Gambar 1. Grafik Persentase Penetasan Telur Penyu

Grafik penetasan telur penyu pada setiap kedalaman sarang yang berbeda menunjukkan rata-rata nilai persentase keberhasilan penetasan terbanyak terdapat pada kedalaman sarang $30 \mathrm{~cm}$ (perlakuan A) dengan nilai persentase penetasan sebesar $78 \%$. untuk kedalaman sarang $40 \mathrm{~cm}$ (perlakuan B) nilai rata-rata persentase keberhasilan penetasan telur penyu sisik sebesar $56.33 \%$ dan perlakuan yang terendah dengan nilai rata-rata persentase penetasan telur penyu sisik terdapat pada kedalaman sarang $50 \mathrm{~cm}$ (Perlakuan C) dengan nilai persentase penetasan 35\%.

Berdasarkan hasil analisis sidik ragam juga menunjukkan bahwa kedalaman sarang memberikan pengaruh terhadap penetasan telur penyu sisik (Eretmochelys imbricate) dengan nilai $F_{\text {hit }}(21.41)>F_{\text {crito.05 }}$ (5.14). Perlakuan yang paling berpengaruh terhadap penetasan telur penyu sisik berdasarkan uji lanjut adalah Perlakuan A $(30 \mathrm{~cm})$, berbeda dengan perlakuan $B(40 \mathrm{~cm})$ dan berbeda dengan perlakuan $C$ $(50 \mathrm{~cm})$.

Faktor kedalaman sarang akan mempengaruhi seberapa besar tekanan pasir terhadap sarang tersebut. tekanan pasir juga dipengaruhi oleh factor dari luar seperti cuaca atau curah hujan. Curah hujan akan mempengaruhi tekstur pasir akan menjadi lebih padat didalam sarang tersebut. Semakin padat pasir dalam sarang akan mempengaruhi perkembangan telur yang di dalam sarang inkubasi. sehingga menyebabkan terganggunya perkembangan embrio dalam telur dan juga bisa menyebabkan kematian bagi tukik yang sudah menetas.

Faktor cuaca akan mempengaruhi juga suhu yang akan masuk kedalam sarang inkubasi. semakin dalam sarang inkubasi penetrasi panas dari suhu akan susah masuk dan tidak stabil. Sebaliknya semakin dangkal kedalaman, temperatur makin stabil, daya tetas tinggi. (Marquez (1990, dalam Dendy, 1999).

\subsection{Kecepatan penetasan telur}

Faktor kedalaman sarang inkubasi juga mempengaruhi kecepatan penetesan telur penyu sisik dibanding pada kondisi normal (secara alami). untuk lebih jelas kecepatan penetasan telur penyu sisik dapat dilihat pada Gambar 2. 


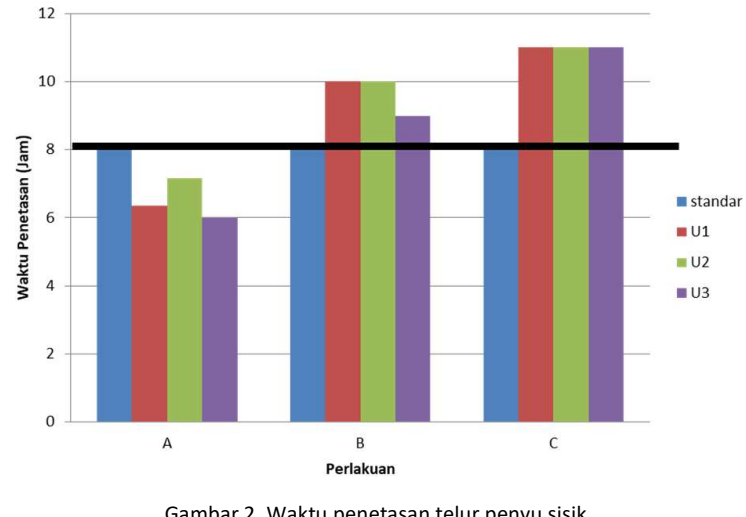

Berdasarkan Gambar 2 menunjukkan bahwa terjadi perbedaan waktu penetasan telur penyu sisik di setiap perlakuan dibandingkan pada waktu penetasan secara alami. waktu penetasan alami menyatakan bahwa pada waktu 56 hari telur penyu sisik sudah menetas. Awal peletakan telur penyu sisik pada jam 8.00 wib. Pada penelitian ini menunjukkan bahwa perlakuan A (kedalaman sarang $30 \mathrm{~cm}$ ) menunjukkan bahwa terjadi pengurangan waktu penetasan rata-rata 1.5 jam lebih cepat. sedangkan untuk perlakuan $B$ dengan kedalaman sarang $40 \mathrm{~cm}$ terjadi penambahan waktu rata-rata 1.67 jam sedangkan perlakuan C kedalaman sarang $50 \mathrm{~cm}$ membutuhkan waktu lebih lama lagi untuk menetas yaitu rata-rata lebih lambat 3 jam.

Hasil analisis sidik ragam menunjukkan bahwa kedalaman sarang mempengaruhi kecepatan penetasan telur penyu dengan nilai $F_{\text {hit }}(70.62)>F_{\text {crito.05 }}$ (5.14). Perlakuan yang paling berpengaruh terhadap kecepatan penetasan telur penyu sisik berdasarkan uji lanjut adalah Perlakuan A $(30 \mathrm{~cm})$, berbeda dengan perlakuan $B(40 \mathrm{~cm})$ dan berbeda dengan perlakuan $C(50 \mathrm{~cm})$. uji lanjut menunjukkan bahwa perlakuan $A(30 \mathrm{~cm})$ berbeda dengan $B(40 \mathrm{~cm})$ dan $C(50 \mathrm{~cm})$.

Kedalaman sarang mempengaruhi kecepatan dari penetesan telur penyu sisik karena berhubungan dengan suhu yang ada didalam sarang dan juga dipengaruhi oleh kecepatan tukik yang sudah menentas untuk keluar dari sarang. Sehingga tukik tersebut membutuhkan waktu untuk keluar dari sarang.

\subsection{Suhu penetasan}

Suhu merupakan factor utama yang akan mempengaruhi proses penetasan dan kecepatan penetasan telur penyu sisik (Eretmochelys imbricata). Selama penelitian nilai parameter suhu dapat dilihar pada Gambar 3.

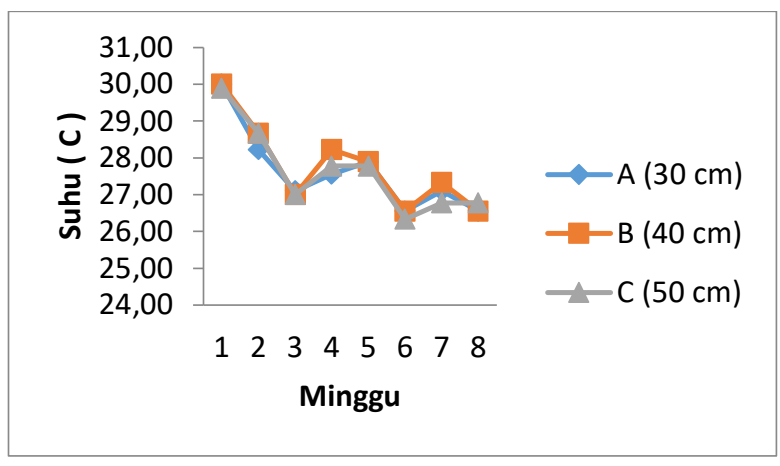

Gambar 3. Pengamatan suhu

Suhu adalah salah satu faktor yang mempengaruhi persentase penetasan telur penyu. Hal ini disebabkan jika ada sirkulasi udara atau oksigen yang masuk kedalam sarang inkubasi maka akan mempercepat proses terbentuknya embrio didalam telur. Suhu selama 8 minggu penetasan disetiap perlakuan berada pada kisaran $26-30{ }^{\circ} \mathrm{C}$. hal ini sesuai pendapat Lutz dan Musick (1997) dalam Rudiana et al (2004) mengatakan bahwa suhu yang masih ditolerir oleh keberhasilan menetas bagi telur penyu adalah $25-34{ }^{\circ} \mathrm{C}$.

Menurut Rudiana et al (2004) Kondisi sarang sangat berpengaruh terhadap keberhasilan menetas telur penyu. Terdapat 2 faktor utama yang berpengaruh langsung terhadap keberhasilan menetas telur penyu selama masa inkubasi yaitu suhu dan kadar air dalam sarang.

Suhu sarang merupakan perpaduan antara suhu lingkungan dengan suhu metabolisme yang berasal dari proses embrionik maka kisaran suhu optimal akan memberikan interaksi dengan perkembangan embrio yang sedang berkembang. Maulana et al (2017) berpendapat suhu yang berada pada pada kisaran yang rendah atau tinggi dari suhu optimal untuk perkembangan embrio akan menghasilkan laju penetasan kurang dari $50 \%$. Dengan kondisi suhu yang demikian maka perkembangan embrio dalam telur akan lebih baik

\section{4. $\quad p H$ substrat penetasan}

Parameter $\mathrm{pH}$ substart inkubasi penetasan telur penyu sisik (Eretmochelys imbricata) selama penelitian dapat dilihat pada Gambar 4.

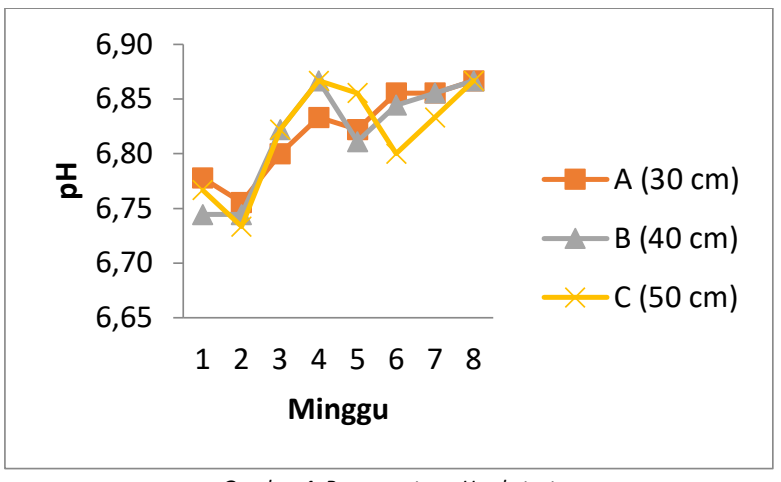

Gambar 4. Pengamatan pH substrat

Pasir pantai cenderung bersifat asam karena kandungan garamnya yang tinggi dan sedikitnya partikel liat dan kurangnya bahan organik. Dari hasil penelitian ini menunjukan nilai $\mathrm{pH}$ pada sarang penetasan telur penyu berkisar antara 6,6-6,9 yang menunjukkan $\mathrm{pH}$ pasir asam dan cenderung netral namun mendukung keberhasilan penetasan telur penyu.

$\mathrm{pH}$ yang sesuai untuk proses penetasan adalah $\mathrm{pH}$ yang asam namun mendekati netral. Jika $\mathrm{pH}$ terlalu asam itu akan berpengaruh pada proses perkembangan tukik, pasir yang ph nya asam termasuk pasir beracun dan tidak bagus untuk proses perkembangan tukik. Adapun kisaran $\mathrm{pH}$ yang tergolong sangat asam adalah 3,8-3,9. (Samosir et al, 2018). pH yang asam juga dapat mengganggu proses pembentukan embrio pada masa inkubasi. Karena pasir yang asam mengngandung logam berat sehingga dapat meganggu proses perkembangan embrio dan pertumbuhan tukik. (Primasatya et al, 2013)

\subsection{Ukuran partikel substrat peneluran}

Menurut Ackerman (1997) dalam Rofiah (2012), penyu menggali sarang dan meletakkan telur-telurnya di sebuah pantai berpasir. Pantai berpasir tempat peneluran penyu merupakan incubator serta memiliki suasana lingkungan yang sesuai bagi perkembangan embrio penyu. Iklim mikro yang sesuai untuk inkubasi telur penyu ditimbulkan dari adanya 
interaksi antara karakter fisik material, penyusun pantai, iklim lokal dan telur-telur dalam sarang. Dari hasil analisis ukuran partikel substrat peneluruan (inkubasi) telur penyu didapati bahwa butiran pasir yang dominan adalah pasir sedang/menengah.Butiran pasir berukuran $0,150 \mathrm{~mm}$ dengan no saringan 100. secara jelas dapat dilihat pada Gambar berikut.

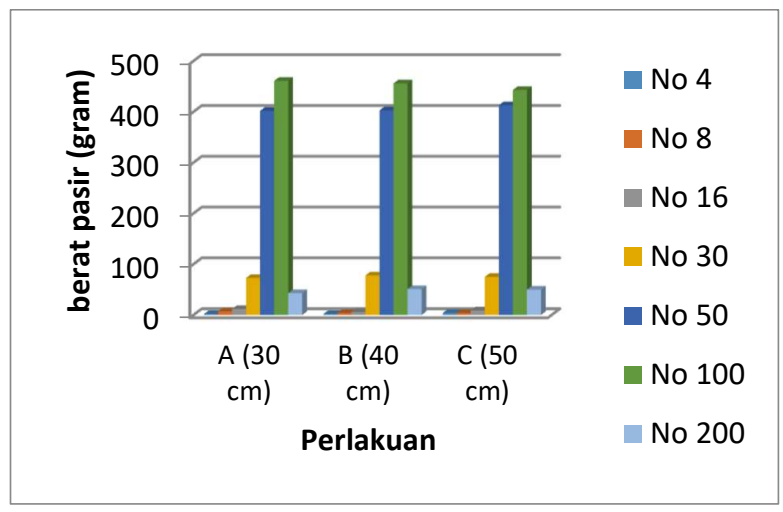

Gambar 5. Berat Pasir Berdasarkan No Ayakan

Pada penelitian ini didapati pasir dengan ciri-ciri pasir yang sangat halus, pasir halus, pasir sedang/menengah, pasir kasar, pasir sangat kasar. Pasir sangat halus merupakan partikel pasir yang melewati semua ukuran wadah pengayakan. Sedangkan pasir halus tertinggal dalam nomor saringan 200 dengan ukuran saringan $0,075 \mathrm{~mm}$, pasir sedang/menengah tertinggal pada nomor saringan 100 dengan ukuran saringan 0,150 $\mathrm{mm}$, sementara pasir kasar tertinggal pada nomor saringan 50 dengan ukuran saringan $0,300 \mathrm{~mm}$, dan pada pasir sangat kasar tertinggal pada nomor saringan 30 dengan ukuran saringan $0,600 \mathrm{~mm}$. sedangkan substrat yang tertinggal pada nomor saringan 16,8 termasuk kedalam golongan kerikil, dan pada nomor saringan 4 dengan ukuran saringan $475 \mathrm{~mm}$ merupakan batu-batuan.

Ukuran partikel substrat peneluran penyu sisik di lokasi penelitian sangat cocok untuk proses inkubasi telur penyu, karena secara keseluruhan partikel subtract peneluran dominan adalah pasir berukuran sedang. Hal ini sesuai dengan pendapat Nybakken (1992) dalam Rofiah (2012), bahwa ukuran butir pasir sangat berpengaruh terhadap sifat pasir sebagai penyangga yang baik bagi perubahan suhu. Sedangkan menurut Dunn, et. al. (1992) dalam Rofiah (2012), umumnya pasir berukuran sedang sampai halus mampu menjadi penyangga suhu yang baik dalam sarang.

Umumnya pasir yang baik untuk proses penetasan telur adalah yang sesuai dengan habitat peneluran penyu. Contohnya pasir yang terdapat di pantai yang bersih, pasir tidak terkontaminasi dengan bakteri dan jamur. Pada penelitian ini sendiri digunakan pasir habitat peneluran penyu sisik dan pasir pantai sekitaran area konservasi.

\section{Kesimpulan}

Berdasarkan hasil penelitian yang telah dilakukan dapat disimpulkan bahwa kedalaman sarang inkubasi telur penyu berpengaruh terhadap persentase penetasan telur penyu Sisik (Eretmochelys imbricate). Didapati bahwa perlakuan terbaik pada perlakuan A dengan kedalaman sarang inkubasi $30 \mathrm{~cm}$ dengan persentase penetasan mencapai $78 \%$. Dengan waktu penetasan lebih cepat dari perlakuan B dan C, pada perlakuan A telur penyu menetas di pukul 06:00 wib

\section{Bibliografi}

Dendy, W. 1999. Penetasan Semi Alami Telur Penyu Sisik di Pulau Segamat Besar Kabupaten Lampung Tengah. Bogor JUrusan Sumber Daya Hutan Fakultas KehutananIPB.

Dermawan, A., Nuitja, I.N.S., Soedharma, D., Halim, M.H., Kusrini, M.D., Lubis, S.B., Alhanif, R., Khazali, M., Murdiah, M., Wahjuhardini, P.L., Setiabudiningsih, Mashar, A. 2009. Pedoman Teknik Pengelolaan Konservasi Penyu. Direktorat Konservasi dan Taman Nasional Laut. Dirjen KP3K, DKP RI Jakarta.

Maulana, R., Adi, W., Muslih, K. 2017. Kedalaman Sarang Semi Alami terhadap Penetasan Telur Penyu Sisik (Eretmochelys Imbricata) di Penangkaran Tukik Babel, Sungai Liat. Jurnal Sumberdaya Perairan Akuatik. 11 (2). 51-57.

Rofiah, A., Hartati, R., Wibowo, E. 2012. Pengaruh naungan sarang terhadap persentase penetasan telur penyu lekang (Lepidochelys olivacea) di Pantai Samas Bantul, Yogyakarta. Journal Of Marine Research. 1(2): 103-108.

Rudiana, E., Ismunarti, D.W., Nirwani, S. 2004. Tingkat keberhasilan Penetasan dan Masa inkubasi Telur Penyu hijau, Chelonia mydas L pada Perbedaan waktu Pemindahan. Ilmu Kelautan. Desember 2004. 9(4): 202 205.

Samosir, H.S., Hernawati, T., Yudhana, A., Haditanojo, W. 2018. Perbedaan sarang Alami Dengan Semi Alami Mempengaruhi Masa Inkubasi Dan Keberhasilan Menetas Penyu Lekang (Lepidochelys olivacea) Pantai Boom Banyuwangi. Jurnal Medik Veteriner. 1(2): 3337.

Primasatya, E., Elfidasari, D., Sugoro, I. 2013. Identifikasi Kandungan Logam Berat Pada Sarang Pasir Penyu Hijau (Chelonia mydas). Kalimantan Timur. Prosiding Seminar Nasional Matematika, Sains, dan Teknologi. 4, B.143B. 150 . 